only 12 fruit and vegetable portions a week; the recommended intake is five portions a day. ${ }^{5}$

There was an association in female patients between mental state and alcohol intake. This association may have arisen by chance as, in all, 36 correlations were calculated. Also, association does not imply causality. Does a high alcohol intake worsen the mental state? Or does a disturbed mental state lead women to drink more?

We conclude that the schizophrenic patients we studied are making poor dietary choices. Assertive programmes to improve diet are necessary.

We thank the patients and staff of the Dumfries and Galloway Mental Health Association and the control subjects for their cooperation; Joan Brown, area dietician, for advice on dietary assessment and provision of training; Heather Barrington for statistical advice; and Mary Muirhead for secretarial help.

Contributors: RMcC initiated and coordinated the study, discussed core ideas, designed the protocol, participated in data analysis, and wrote the paper. JP initiated and coordinated the study, discussed core ideas, designed the protocol, participated in data analysis, and edited the paper. EM discussed core ideas, participated in clinical data collection and data analysis, and contributed to the paper. DT-S and JH discussed core ideas, participated in clinical data collection, and contributed to the paper $\mathrm{CB}$ and DW discussed core ideas, analysed blood samples, and contributed to the paper. RMcC and JP are guarantors for the study.

Funding: None

Conflict of interest: None

1 The Scottish diet. Edinburgh: Scottish Office Home and Health Department, 1993. (Report of a working party to the chief medical officer for Scotland.)

2 Yarnell JWG, Fehily AM, Milbank JF, Sweetnam PM, Walker CL. A short dietary questionnaire for use in an epidemiological survey: comparison with weighed dietary records. Human Nutrition:Applied Nutrition 1983:37A:103-12.

3 Catignani GL, Bieri JG. Simultaneous determination of retinol and a-tocopherol in serum or plasma by liquid chromatography. Clin Chem $1983 ; 29: 708-12$

Department of Health. Dietary reference values for food energy and nutrients in the United Kingdom. London: HMSO, 1991.

5 Heimendinger J, van Duvn MAS. Dietary behaviour change: the challenge of recasting the role of fruit and vegetables and the American diet. Am J Clin Nutr 1995;61:1397-401S.

(Accepted 26 June 1998)

\title{
Effect of fundholding on removing patients from general practitioners' lists: retrospective study
}

\author{
Dermot O’Reilly, Keith Steele, Barry Merriman, Andrew Gilliland, Scott Brown
}

Fundholding by general practitioners was introduced during NHS reforms in 1989. Little is known about its impact on the quality of patient care. ${ }^{1}$ One measure of this impact is the rate at which practices decide they do not wish to continue to provide general medical services for patients and remove them from their lists ("removal at general practitioner's request"). In Northern Ireland the rate of the removing patients from practitioners' lists increased after the introduction of fundholding in $1993^{2}$ which suggests that there is a relation between fundholding and removing patients from lists. We report an investigation to determine if becoming a fundholding practice changed the rates of removing patients from practice lists.

\section{Methods and results}

For the past 15 years the Central Services Agency has maintained a register of all patients removed from lists at a general practitioner's request. The database does not contain patients who have been removed for reasons such as leaving the country or moving outside the practice area. However, records are retained if the patient has died or emigrated. Demographic data were obtained for each patient removed from a list during the study, and each record was coded according to the fundholding status of the practitioner.

There were four waves of fundholding between 1987 and 1996; the first began in April 1993 and each new wave followed in April of the succeeding year. The data were divided into three phases for each fundholding practice: fundholding, preparatory year (the financial year prior to fundholding), and prepreparatory period (from January 1987 until the start of the preparatory year). The removal of an individual patient or family unit was counted as one decision, and only first time removals within the 10 year period were analysed. Rates for first removal decisions per 10000 person years were calculated for each period as previously described. ${ }^{2}$ Rates for non-fundholding practices were also examined using the commencement date of each wave of fundholding to artificially divide the data into before and after periods. In April 1996 there were 419 general practitioners in 114 practices serving 724104 patients.

Results of the analysis are shown in the table.There was no increase in the rate of removing patients from non-fundholding practices. Among fundholding practices the rate of removing patients increased from $1.8 / 10000$ person years in the prepreparatory period to $2.2 / 10000$ person years during the fundholding period; this was an increase of $21.4 \%$ (95\% confidence interval $7.4 \%$ to $35.5 \%$ ) Practices that became fundholding practices in later years removed patients more frequently and started removing patients at higher rates during the preparatory year.

\section{Comment}

The rates of removing patients from general practitioners' lists are influenced by characteristics of both the practice and population. ${ }^{2}$ In this analysis practices were compared with their earlier performance obviating these potentially confounding variables. The increases in the rates among fundholders are therefore intrinsically related to fundholding status. The different rates of removal occurring between successive waves of fundholders and between fundholders and nonfundholders could be attributed to differences in socio-
Health and Social Care Research Unit, Queen's University of Belfast, BT12 6BJ Dermot O'Reilly, deputy director Barry Merriman, research assistant

Department of General Practice, Queen's University of Belfast

Keith Steele, senior lecturer Andrew Gilliland, senior lecturer

Royal College of General Physicians Research Practice, Mountsandel Surgery, Coleraine BT52 1JB

Scott Brown, general practitioner Correspondence to: Dr O'Reilly d.oreilly@qub.ac.uk

BMJ 1998;317:785-6 
Rates of removing patients from general practitioners' lists according to fundholding status and time of becoming a fundholding practice

\begin{tabular}{|c|c|c|c|}
\hline & $\begin{array}{l}\text { No of patients } \\
\text { removed from list }\end{array}$ & Person years & $\begin{array}{l}\text { Rate of removal } / 10000 \\
\text { person years }(95 \% \mathrm{Cl})\end{array}$ \\
\hline \multicolumn{4}{|l|}{ Fundholding practices* } \\
\hline \multicolumn{4}{|l|}{ April 1993: } \\
\hline Prepreparatory period & 126 & 1066874 & $1.2(1.0$ to 1.4$)$ \\
\hline Preparatory year & 21 & 203214 & $1.0(0.6$ to 1.6$)$ \\
\hline Fundholding & 140 & 762053 & 1.8 (1.5 to 2.2 ) \\
\hline \multicolumn{4}{|l|}{ April 1994: } \\
\hline Prepreparatory period & 218 & 1348525 & 1.6 (1.4 to 1.8$)$ \\
\hline Preparatory year & 27 & 215764 & $1.3(0.8$ to 1.8$)$ \\
\hline Fundholding & 141 & 593351 & 2.4 (2.0 to 2.8$)$ \\
\hline \multicolumn{4}{|l|}{ April 1995: } \\
\hline Prepreparatory period & 125 & 493268 & 2.5 (2.1 to 3.0$)$ \\
\hline Preparatory year & 26 & 68037 & 3.8 (2.5 to 5.6$)$ \\
\hline Fundholding & 27 & 119065 & 2.3 (1.5 to 3.3 ) \\
\hline \multicolumn{4}{|l|}{ April 1996: } \\
\hline Prepreparatory period & 440 & 2114203 & 2.1 (1.9 to 2.3) \\
\hline Preparatory year & 113 & 256267 & 4.4 (3.6 to 5.3$)$ \\
\hline Fundholding & 58 & 192200 & 3.0 (2.3 to 3.9$)$ \\
\hline \multicolumn{4}{|l|}{ Fundholding practices overall: } \\
\hline $\begin{array}{c}\text { Prepreparatory period } \\
\end{array}$ & 909 & 5022870 & 1.8 (1.7 to 1.9$)$ \\
\hline Preparatory year & 187 & 743282 & 2.5 (2.2 to 2.9$)$ \\
\hline Fundholding & 366 & 1666668 & 2.2 (2.0 to 2.4$)$ \\
\hline \multicolumn{4}{|l|}{ Non-fundholding practices } \\
\hline \multicolumn{4}{|l|}{ April 1993: } \\
\hline Before & 1415 & 6242994 & 2.3 (2.2 to 2.4$)$ \\
\hline After & 871 & 3745796 & 2.3 (2.2 to 2.5$)$ \\
\hline \multicolumn{4}{|l|}{ April 1994: } \\
\hline Before & 1622 & 7241873 & 2.2 (2.1 to 2.4$)$ \\
\hline After & 664 & 2746917 & 2.4 (2.2 to 2.6$)$ \\
\hline \multicolumn{4}{|l|}{ April 1995: } \\
\hline Before & 1870 & 8240752 & 2.3 (2.2 to 2.4$)$ \\
\hline After & 416 & 1748038 & 2.4 (2.2 to 2.6$)$ \\
\hline \multicolumn{4}{|l|}{ April 1996: } \\
\hline Before & 2117 & 9239631 & $2.3(2.2$ to 2.4$)$ \\
\hline After & 169 & 749159 & 2.3 (2.0 to 2.6$)$ \\
\hline Non-fundholding practices overall & 2286 & 9988790 & 2.3 (2.2 to 2.4$)$ \\
\hline
\end{tabular}

${ }^{*}$ The prepreparatory period extends from January 1987 until the start of the preparatory year. The preparatory year covers the financial year before fundholding began

economic and demographic characteristics of practice populations arising from a selection bias in practices that became fundholding practices. Other factors, such as the 1990 contract (which substantively altered the terms of service of all general practitioners in the United Kingdom), cannot explain the increase, as similar changes were not found for the non-fundholding practices.

It is unclear why the rate of removing patients has increased but "list cleaning" (removing patients who have died or left the practice area from lists) can be discounted. The database used in this study is maintained separately from the patient registration data within the Central Services Agency and contains only removals made at the request of general practitioners. Trained staff undertake validation checks which include contacting practitioners and writing to patients to inform them of the category of removal. Removals because of death are processed differently, and follow up procedures would identify a misclassification.

The public perception is that financial factors motivate fundholders to remove patients from their lists. ${ }^{3}$ In the United States where healthcare systems provide financial incentives "adverse selection" is common; it has been suggested that the reforms in the NHS could stimulate similar effects. ${ }^{4}$ Increased rates of removing patient may, however, reflect the additional workload and pressures of fundholding ${ }^{5}$ rather than attempts at financial gain.

The decision to remove patients occurs comparatively infrequently and our results suggest that a fundholding practice with a list size of 5000 patients would be making one additional removal decision every five years. Our findings suggest that other areas of health care that experience large increases in workload, or where the potential for adverse selection exists, should be monitored.

Contributors: KS and DO'R had the original idea for the study. DO'R, KS, AG, and SB designed the form for data collection. DO'R and BM were responsible for the analysis of the data. DO'R, KS, AG, SB, and BM wrote the paper. DO'R is the guarantor for the paper.

Funding: This study was assisted by a grant from the Royal College of General Practitioners.

Conflict of interest: None.

1 Dixon J, Glennerester $\mathrm{H}$. What do we know about fundholding in general practice? BMJ 1995; 311:727-30

2 O'Reilly D, Steele K, Gilliland D, Merriman B, Brown S. Patient removals from general practitioner lists in Northern Ireland: 1987-1996. Br J Gen Pract (in press).

3 Laurance J. Some dentists and GPs are turning away expensive patients. Times 1996; Sept 25:10.

4 Scheffler R. Adverse selection: the Achilles heel of the NHS reforms. Lancet 1989:i:950-2.

5 Matsaganis M, Glennerester $\mathrm{H}$. The threat of "cream-skimming" in the post-reform NHS.J Health Economics 1994;13:31-64. (Accepted 17 July 1998)

\section{Corrections}

Will the fudge on equity sustain the NHS into the next millennium?

In the article by Mays and Keen (4 July, pp 66-9) the third sentence in the first paragraph of the section about arguments for changes, contained an error. The sentence should have read: "Although it is difficult to believe when you are on an NHS waiting list, people in the United Kingdom are more satisfied with healthcare arrangements than are people in the United States and Sweden, but less satisfied than people in Canada; these three countries all spend more than the United Kingdom on health care."."

Excess mortality after human albumin administration in critically ill patients

In the editorial by Martin Offringa (25 July, pp 223-4) the reference cited towards the end of the penultimate paragraph should have been reference 4 , not 2 .

Cardiac arrests outside hospital

The opening sentence of the editorial by Tom Evans (4 April, pp 1031-2) should have read:

"Twenty five years after the original epidemiological studies ${ }^{12}$ two thirds of all patients who die with acute coronary events still do so before reaching a hospital ( $\mathrm{p}$ 1065)."

Randomised controlled trial comparing effectiveness and acceptability of an early discharge, hospital at home scheme with acute hospital care

An error occurred in this article by Suzanne $\mathrm{H}$ Richards and colleagues (13 June, pp 1796-801). In table 6 (p 1800) the difference $(95 \%$ confidence interval) for "Information on treatment (as much as wanted)" should have been -3.2 ( -15.7 to 9.3 ) (rather than $-3.2(-11.2$ to 17.8$)$ ). This does not, however, affect the interpretation of the results. 